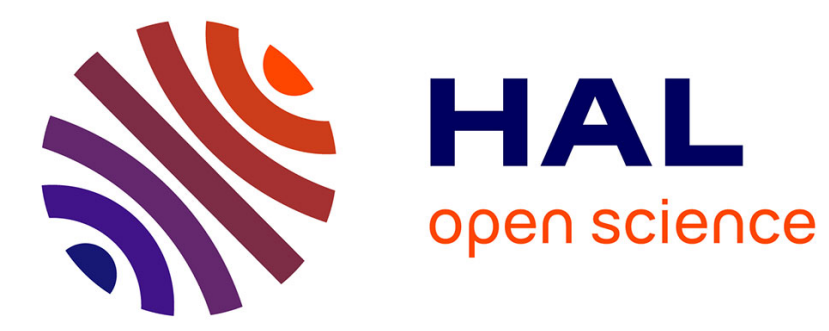

\title{
Phase Transitions In Partially Spin-Polarized 3he
} M. Barranco, A. Polls, S. Stringari, P. Nacher, F. Laloë

\section{To cite this version:}

M. Barranco, A. Polls, S. Stringari, P. Nacher, F. Laloë. Phase Transitions In Partially Spin-Polarized 3he. Journal de Physique Colloques, 1987, 48 (C2), pp.C2-101-C2-106. 10.1051/jphyscol:1987216 . jpa-00226481

\section{HAL Id: jpa-00226481 https://hal.science/jpa-00226481}

Submitted on 1 Jan 1987

HAL is a multi-disciplinary open access archive for the deposit and dissemination of scientific research documents, whether they are published or not. The documents may come from teaching and research institutions in France or abroad, or from public or private research centers.
L'archive ouverte pluridisciplinaire HAL, est destinée au dépôt et à la diffusion de documents scientifiques de niveau recherche, publiés ou non, émanant des établissements d'enseignement et de recherche français ou étrangers, des laboratoires publics ou privés. 
JOURNAL DE PHYSIQUE

Colloque C2, supplément au $n^{\circ} 6$, Tome 48, juin 1987

PHASE TRANSITIONS IN PARTIALLY SPIN-POLARIZED ${ }^{3} \mathrm{He}$

\author{
M. BARRANCO, A. POLLS, S. STRINGARI* , P.J. NACHER* * and \\ F. LALOË** \\ Departament d'Estructura i Constituents de la Matèria, \\ Facultat de Fisica, Universitat de Barcelona, Diagonal 647, \\ SP-08028 Barcelona, Spain \\ *Dipartimento di Fisica, Università di Trento, \\ I-38050 Povo (Trento), Italy \\ *" Laboratoire de Physique de I'Ecole Normale Supérieure. \\ 24, rue Lhomond, F-75005 paris, France
}

\title{
Résumé
}

Nous presentons les diagrames d'equilibre liquide-gaz pour l'helium trois partiellement polarise. A basses températures, nous trouvons des phénomenes intéressants tels que le metamagnetisme en phase liquide ou une surpolarisation du liquide.

\section{Abstract}

We present liquid-gas equilibrium phase diagrams for partially spin-polarized ${ }^{3}$ he. At low temperatures, interesting phenomena such as liquid metamagnetism and liquid overpolarization have been found.

\section{Introduction}

The study of phase transitions in spin polarized 3 He is a subject of growing interest. At high pressures, the results so far obtained (1) might indicate the existence of a metamagnetic, or near it, transition in the liquid phase. In this contribution, we want to investigate the properties of polarized she at lower pressures, in particular at the vapor pressure. This study has been prompted by some experiments on the liquid-gas phase transition which are now in progress at the Ecole Normale de Paris (2).

To investigate liquid-gas (and liquid-Iiquid) phase transitions, we resort to a simple model already employed in Nuclear Physics ( 3 ). It is based on the use of skyrme-like forces in the framework of a mean field approach (4). A more detailed description of the method as well as further results can be found in refs 5 and 6 .

\section{The formalism}

A convenient thermodynamic potential to describe the system is the free energy density that per unit volume reads

$$
f(\rho, M, T)=E_{n}(\rho, M, T)+E_{v}(\rho, M, T)
$$

where $\rho$ is the number density, $\rho=N / V$, $T$ is the temperature and $M$ the magnetization

$$
M=\left(\rho^{\hat{T}}-\rho^{t}\right) / \rho
$$

$\rho t$ and $\rho$ t are the spin up (down) partial densities. In expression 1 , $f_{n 1}$ is the free energy density of a non-interacting Fermi gas ( 7 ) and $f_{v}$ is the contribution due to the interactions. This is the key ingredient for which we have taken the following function: 


$$
\begin{array}{r}
f=1 / 2\left(b_{0}+b_{1} M^{2}+b_{2} M^{4}\right) \rho^{2}+ \\
1 / 2\left(c_{0}+c_{1} M^{2}+c_{2} M^{4}\right) \rho^{2+\sigma}
\end{array}
$$

To fix the coefficients entering eg. 3 we have used as much experimental information as possible, which is mainly available for $M$ around 0 .

First of all, the values of $b_{0}$, co and $\sigma$ at $T=0$ were fixed in order to reproduce the experimental values of the energy per particle $E_{0}$, equilibrium density $\rho_{0}$ and compressibility $\mathbf{S}$ of unpolarized liguid ${ }^{5}$ He (5). Next, the coefficient bo was made $T$-dependent and fixed to exactly reproduce the vapor pressure of unpolarized He. To obtain $b_{1}(T)$ and $c_{1}(T)$, we have used the magnetic susceptibility $\mathcal{X}$

$$
\frac{c}{\chi}=\left.\frac{1}{\rho^{2}} \frac{\partial^{2} f}{\partial M^{2}}\right|_{T}
$$

for which there are experimental results at $M=0$. In eq. 4, $C$ is the Curie's constant.

The necessity of at least $M^{4}$ terms in eg. 3 stems from experimental facts and theoretical arguments. Indeed, at $M \sim 0$ it is known experimentally that it is easier to magnetize the vapor than the liquid. Consequently, in the liquid-gas equilibrium, near M=0 the phase diagram would be that of fig. 1, where we show the pressure P as a function of $M$ for a given $T$ (L reads for the liquid. $G$ for the gas in equilibrium with it). If $P(M)$ were always an increasing function of $M$, as it is the case of fig. 1, eq. 3 without $M^{4}$ terms would be fine. However, it is easy to show that this is not so for a $11 \mathrm{~T}$.

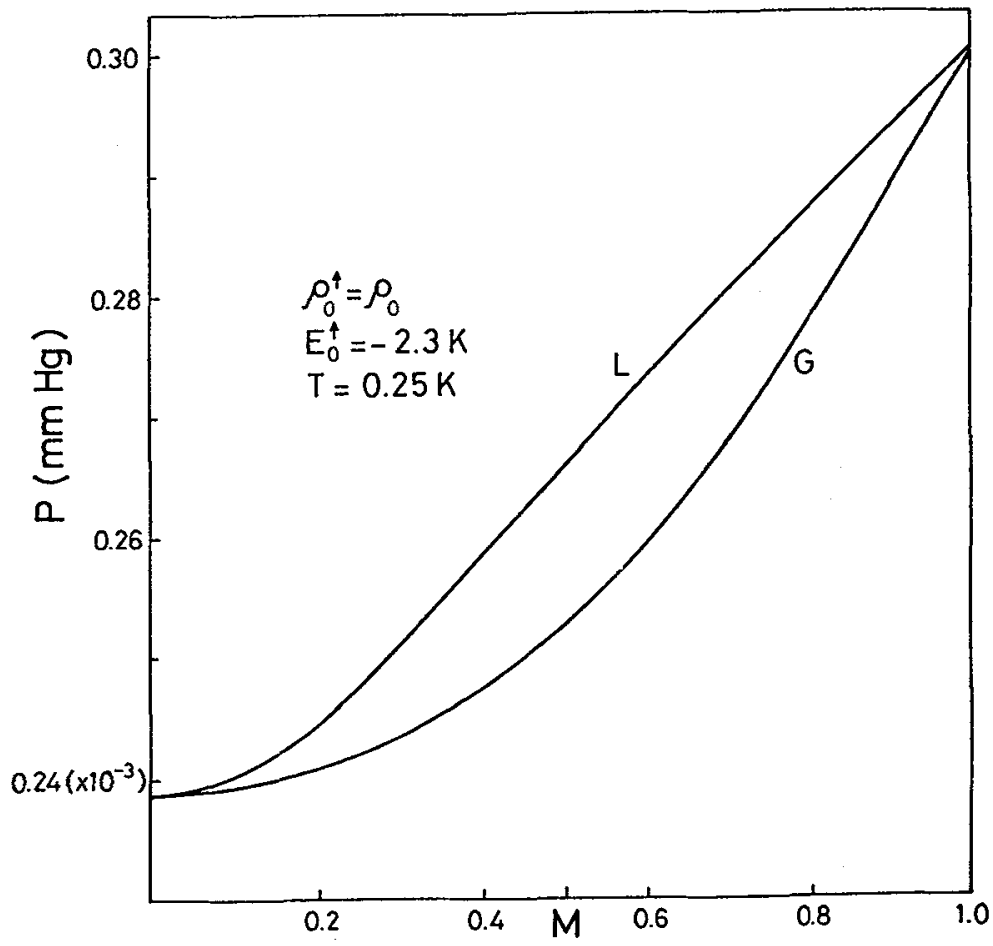

Figure 1 
To see how it comes about, let us consider a very low $T$ and write the pressures $P(P \uparrow)$ of the $M=O(1)$ vapor as a function of the energy per particle $E_{o}\left(\mathbb{E}_{0} \mathbf{t}\right)$ :

$$
\begin{aligned}
& P=A T^{5 / 2} \exp \left(E_{0} / T\right) \\
& P \uparrow=2 A T^{5 / 2} \exp \left(E_{0} \uparrow / T\right)
\end{aligned}
$$

where $A$ is a constant. Since $\left|E_{0} \uparrow\right|<\left|E_{0}\right|$, at $T$ low enough we have $P \uparrow>P$. But when $T$ increases, there is a temperature $T^{*}$ for which both pressures are the same

$$
T^{*}=\left(E_{0} t-E_{0}\right) / \ln 2=\Delta E / \ln 2
$$

and from $T^{*}$ up. $P>P \uparrow$. Recent calculations ( 8 ) show that $E_{0} \sim E_{0}$ and $\rho_{0} \uparrow \sim \rho_{0}$. That makes $T^{*}$ rather small. For example, if $\Delta \mathrm{E}=0.2 \mathrm{~K}$, $\mathrm{T}^{*} \sim 0.3 \mathrm{~K}$. much smaller than the critical temperature of ${ }^{3} \mathrm{He}$ (5) ( $\mathrm{T}^{*}$ estimated from eg. 6 can be accurate only if $T^{*}$ is not very high. For $\Delta \mathrm{E}=0.2 \mathrm{~K}$ our calculations yield $\mathrm{T}^{*} \sim 0.5$ instead of $0.3 \mathrm{~K}$ ). We thus conclude that in order to bend down the $P(M)$ curve, we do need $M^{4}$ terms. Finally, the values of $b_{2}(T)$ and $c_{2}(T)$ are essentially fixed by the values of the experimentaliy unknown quantities $E_{0} \uparrow$ and $\rho_{0} \uparrow$ (6) which are the free parameters of our model.

The presence of $M^{4}$ terms in eq. 3 makes the phenomenom of liquid metamagnetism (divergence of $\mathcal{X}(M)$ for some values of $M$ ) possible. For given values of $\rho$ and $T$, the function $\boldsymbol{X}(M)$ becomes negative in some range of values of $M$. Regions of negative $\chi$ or negative compressibility $K$ are instability regions and the system has to separate in several phases that differ in density and/or magnetization.

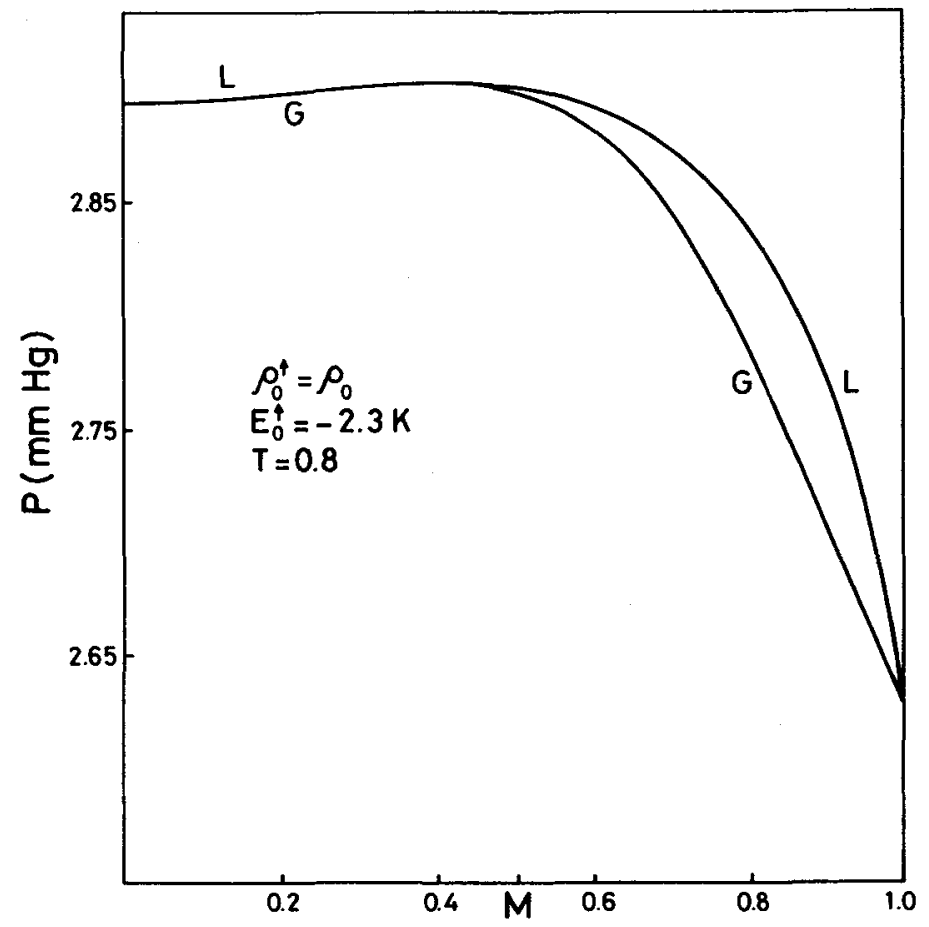




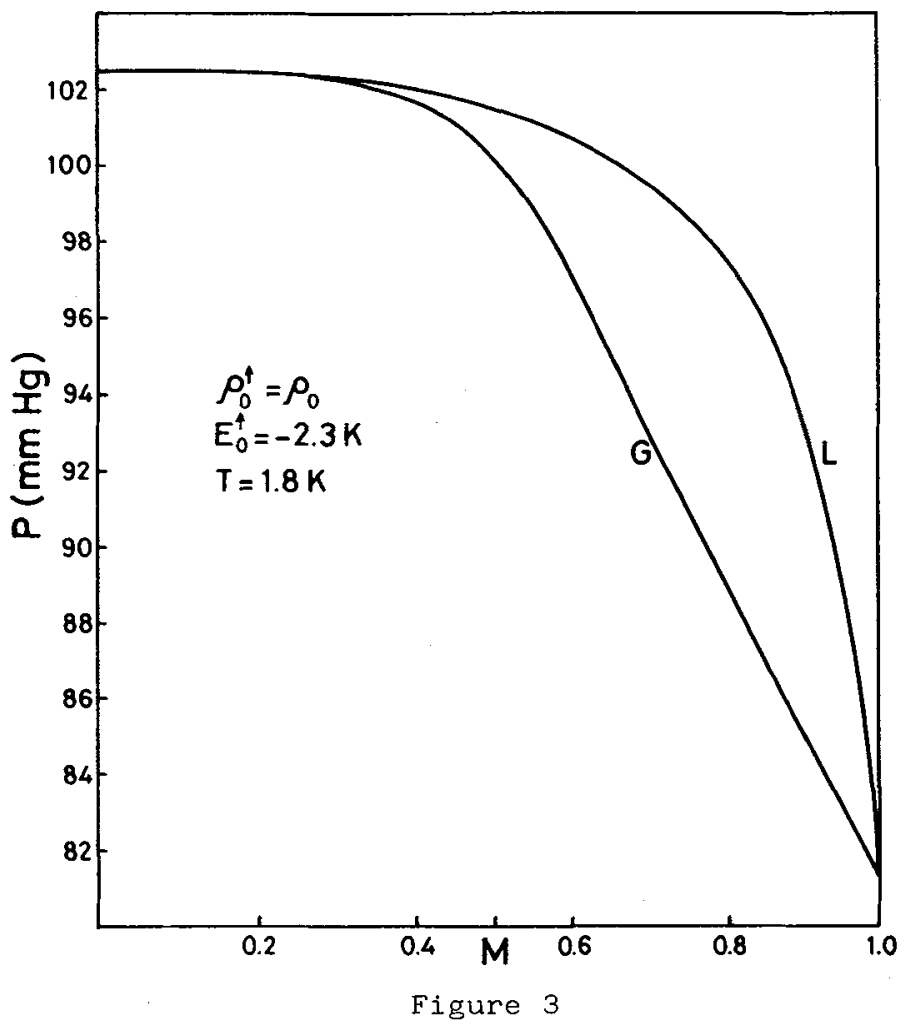

Results

Typical phase diagrams for selected values of $T$ are shown in figs. 1-5. Eigures 1 to 3 correspond to Eol=-2.3 $\mathrm{K}$ (this energy is the more recent theoretical estimate, see ref. 8 ; the results are rather insensitive to the value of $S_{0} \uparrow$ which is also estimated in that ref. to be smaller than $\rho_{0}$ ), whereas figs. 4 and 5 correspond to $E_{0} T=-2.4 \mathrm{~K}$.

In fig. l we present the situation $T<T^{*}$ whereas figs. 2 and 3 correspond to $T>T^{*}$. One may see in fig. 3 that for $M \geq 0.4$ the liquid is more magnetized than the vapor, in contradistinction with fig. 1. The same phenomenon of liquid overpolarization is presented in fig. 4 ( $\mathrm{T}^{*}$ for $\mathrm{E}_{0} \mathrm{t}=-2.4 \mathrm{~K}$ is $\sim 0.2 \mathrm{~K}$ ).

Figure 5 is the result of combining magnetic $(x<0)$ and mechanical $(\mathbb{K}<0)$ instabilities. At low pressures we have a liquid -gas equilibrium that shows again liquid overpolarization. At high pressures, two liquids with rather different magnetizations and similar densities are in thermodynamical equilibrium. When $P$ decreases, there is a point where two liquids are in equilibrium with a common vapor of intermediate $M$ (triple line). We have not found a quadruple point in the calculations performed with our model functional, eq. 3 .

Finaliy, figure 6 shows $\chi(M)$ for $\mathrm{E}_{0} \mathrm{~T}=-2.3 \mathrm{~K}$ at $\mathrm{T}=0.6 \mathrm{~K}$. In this figure, the curve labeled $C L$ corresponds to the classical gas, which is a good approximation for the vapor at this temperature. NIFG represents the non-interacting Eermi gas susceptibility and the solid line is $X(M)$ calculated from eqs. 1,3 and 4 . Notice that near $M=0$, the magnetic susceptibility of the gas is larger than that of the liquid, whereas near $M=1$ the opposite occurs. This is so because $T>$ $T^{*}$ and is in agreement with the situation shown in figures 2 and 3 . 


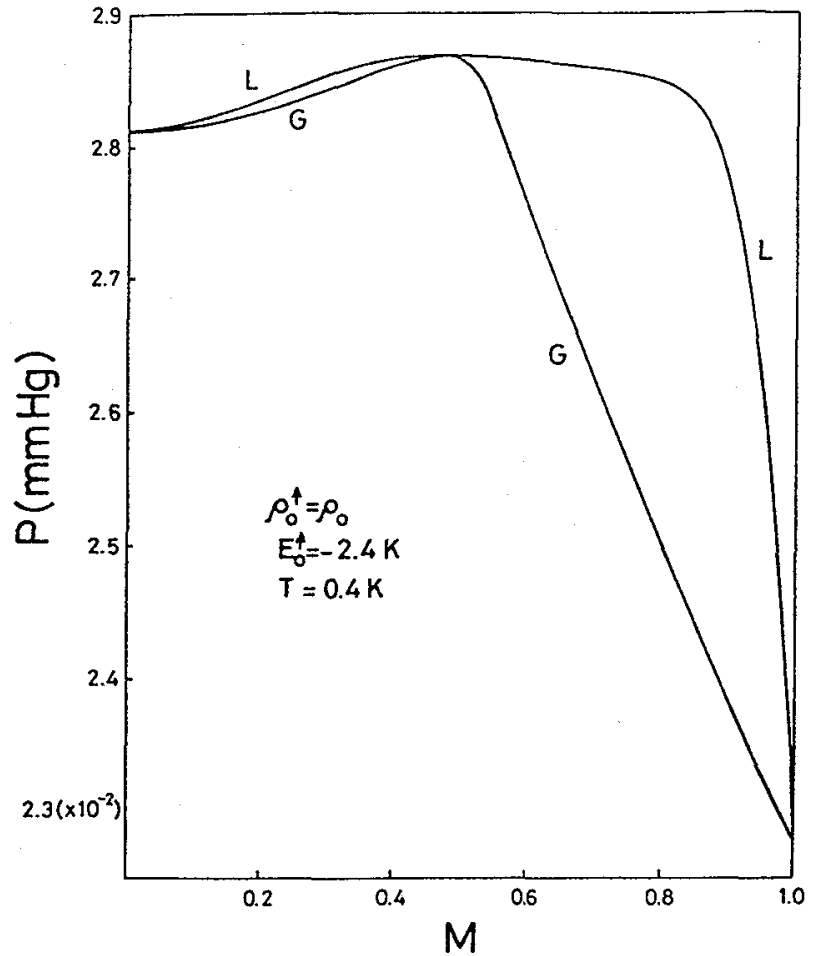

Figure 4

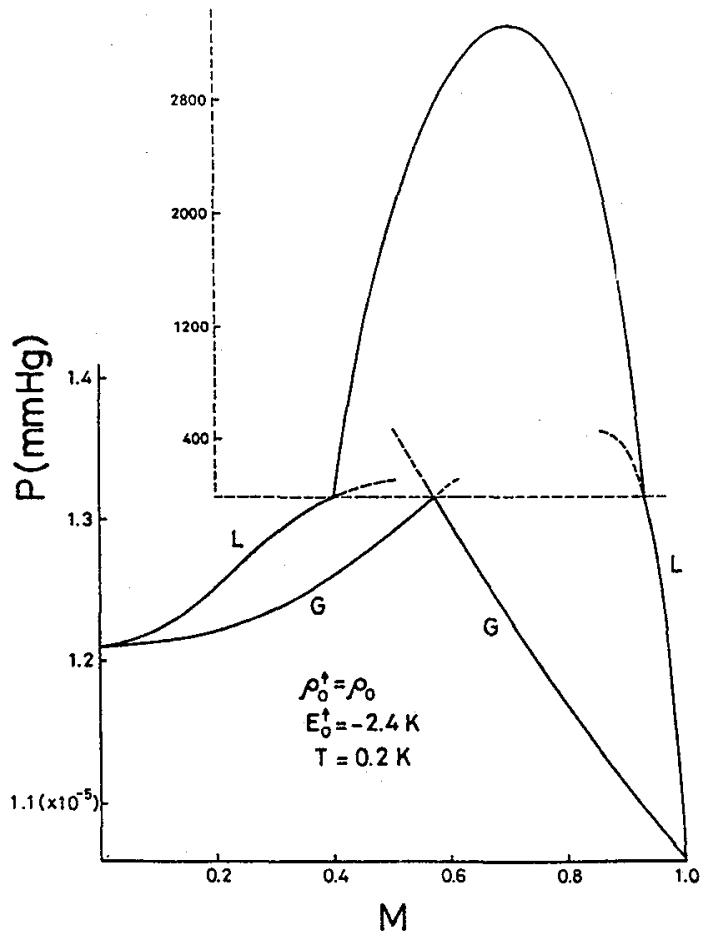

Figure 5 


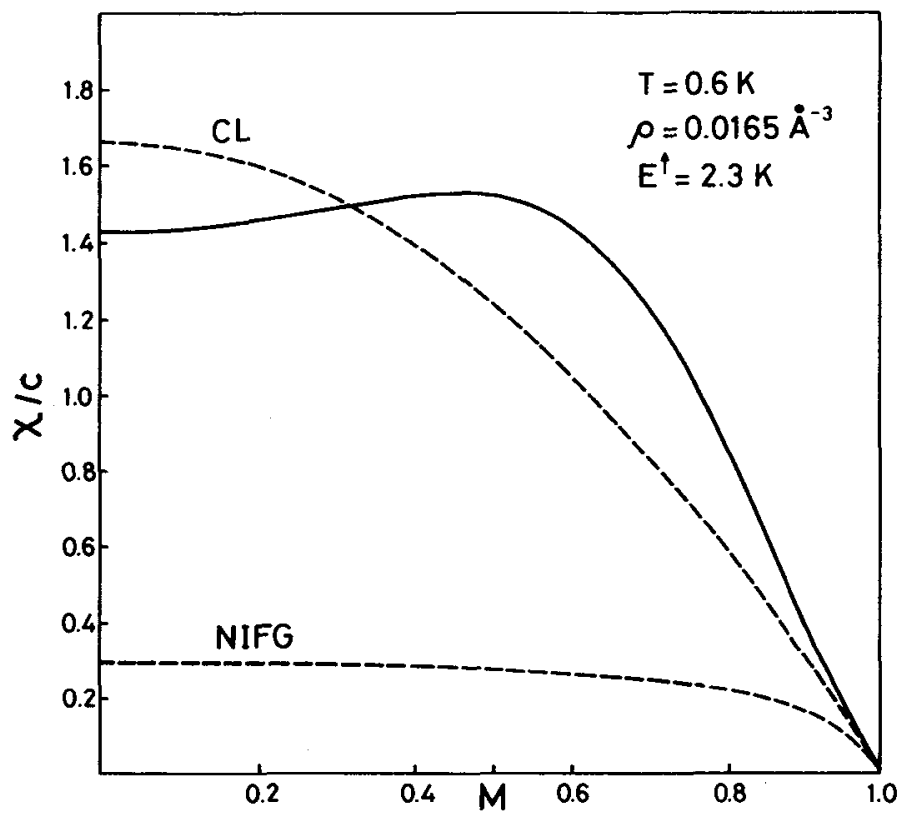

Figure 6

\section{Conclusions}

Our simple model predicts interesting physical situations and shows the key role played by $E_{0} \uparrow$ in the thermodynamics of partially polarized she. Our predictions can be of some relevance for future experiments. We have found that one has to go beyond MN 0.5 to find the most interesting effects.

Even if metamagnetism does not show up, situations near it might well be met (figs. 2 and 3 ), playing an important role (9). One could imagine purely thermal overpolarization methods taking advantage of the particular shape of these diagrams.

This work has been supported in part by the CAICYT (Spain), grant PB85-0072-C02-00

\section{References}

1.- G. Bonfait et al, Europhys. Lett 1 (1986)521

2.- G. Tastevin, P.J. Nacher, L. Wiesenfeld and M. Leduc, private communication

3.- M. Barranco and J.R. Buchler, Phys. Rev. C22(1980)1729

4. - S. Stringari. Europhys. Lett. 2(1986)639

5.- M. Barranco, A. Polls and S. Stringari, "liquid-gas phase transition in ${ }^{3} \mathrm{He} "$, J. de Phys. (Paris). in print (June 1987).

6.- S. Stringari et al "Spin-polarized ${ }^{3} \mathrm{He}$ : Liquid-gas equilibrium", J. de Phys. (Paris), in print (August 1987).

7.- R.K. Pathria, Statistical Mechanics. Pergamon Press (1972)

8.- J.P. Bouchaud and C. Lhuillier, submitted to Europhys. Lett, and refs. therein.

9.- K.S. Bedell and C. Sánchez-Castro, Phys. Rev. Lett 57(1986)854 